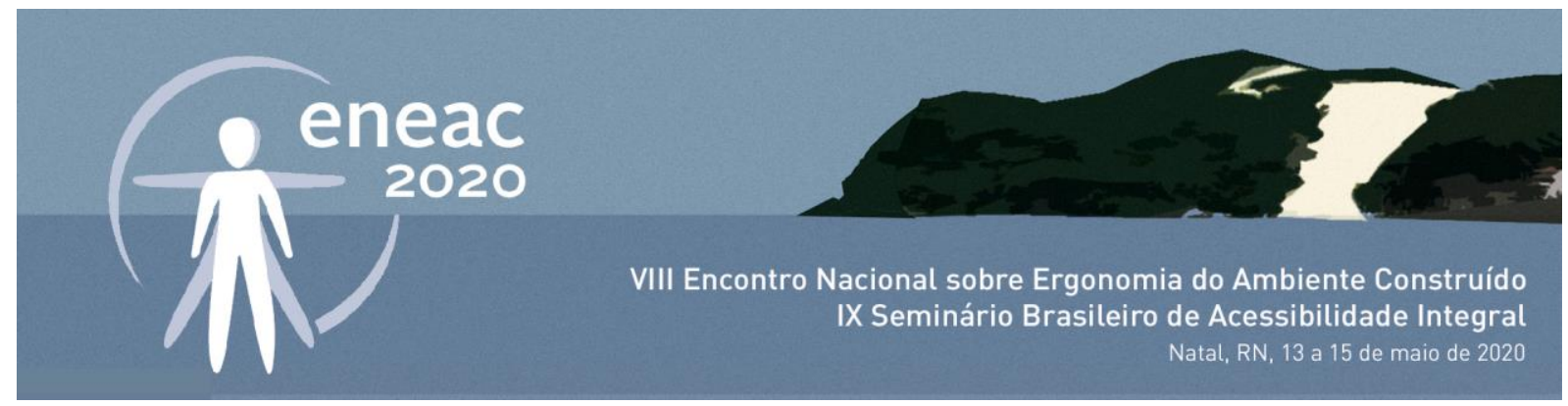

\title{
Capacitando o olhar, sensibilizando para o projetar: Construindo mapas táteis para espaços urbanos.
}

\author{
Empowering the eye, raising awareness to project it: Building \\ tactile maps for urban spaces.
}

EDUARDO AUGUSTO MONTEIRO DE ALMEIDA Mestrando em Arquitetura e Urbanismo, UFPB, eduardoamda.arq@gmail.com

ANGELINA DIAS LEÃO COSTA

Doutorado em Engenharia Civil, UFPB, angelinadlcosta@yahoo.com.br

\section{RESUMO}

A acessibilidade tem despertado o interesse de diversas áreas de conhecimento e seus respectivos profissionais têm procurado ampliar seus conhecimentos. A arquitetura e urbanismo apoiados na psicologia busca compreender os usuários, suas necessidades e relações com o ambiente construído. Ao despertar no projetista a sensibilidade de compreender as necessidades específicas de usuários diversos, projeta-se de forma mais universal, e, portanto, com mais qualidade. Contudo, para se atenderem necessidades de orientação e mobilidade de toda a comunidade, por exemplo, em ambientes universitários, foi desenvolvido uma proposta um mapa tátil. 0 processo metodológico multimétodos adotado, apresenta como uma de suas etapas iniciais o walkthrough - um método de análise ambiental e comportamental dos usuários a partir do olhar do pesquisador, que permite uma real e peculiar aproximação com o objeto de estudo. Este artigo objetiva demonstrar a importância de sua aplicação walkthrough no processo de projetação de mapas táteis para um campus universitário, enfatizando a fidedignidade e qualidade dos dados e informações obtidos. Serão apresentados como resultados, os mapas e tabelas elaborados a partir do extraído da etapa metodológica com os quais fica justificada a importância e necessidade da aplicação do walkthrough no processo de projetação de mapas táteis.

PALAVRAS-CHAVE: Projetar, Walkthrough, Mapa Tátil, Usuário, Campus Universitário.

\section{ABSTRACT}

Accessibility has aroused the interest of several areas of knowledge and their respective professionals have sought to expand their knowledge. Architecture and urbanism supported by psychology seeks to understand users, their needs and relationships with the built environment. When awakening in the designer the sensitivity to understand the specific needs of different users, it is projected in a more universal way, and therefore, with more quality. However, in order to meet the needs of orientation 


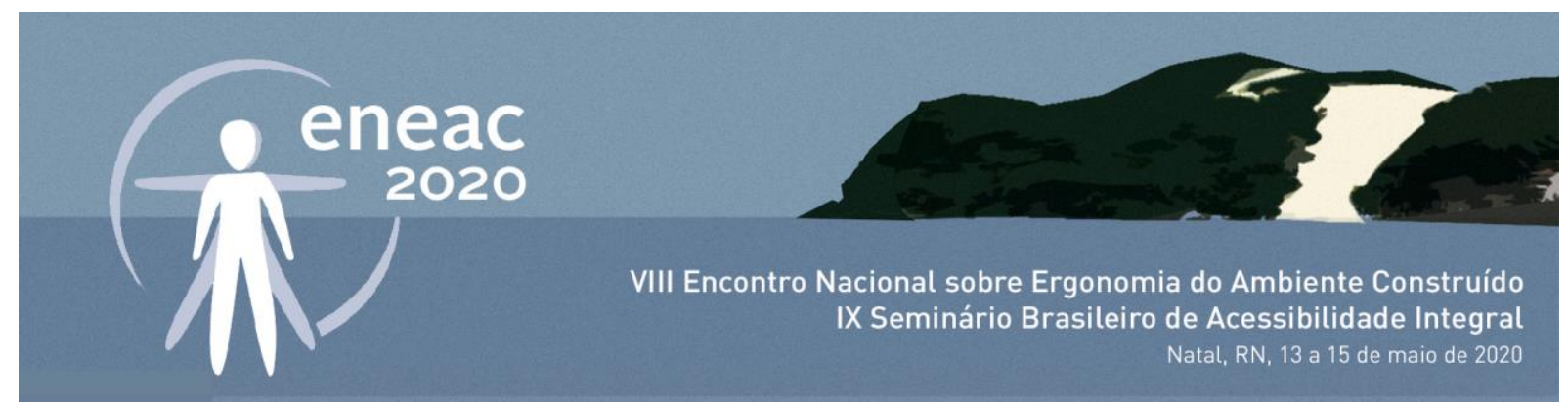

and mobility of the whole community, for example, in university environments, a tactile map proposal was developed. The multi-method methodological process adopted, presents walkthrough as one of its initial stages - a method of environmental and behavioral analysis of users from the researcher's point of view, which allows for a real and peculiar approximation with the object of study. This article aims to demonstrate the importance of its walkthrough application in the process of designing tactile maps for a university campus, emphasizing the reliability and quality of the data and information obtained. As a result, the maps and tables drawn from the extracted from the methodological stage will be presented, with which the importance and need for the application of the walkthrough in the process of projecting tactile maps is justified.

KEYWORDS: Design, Walkthrough, Touch Map, User, University Campus.

\section{INTRODUÇÃO}

A inacessibilidade é vivenciada tanto nos espaços urbanos como edificados, pelos usuários de Campi Universitários brasileiros e, de acordo com Garcia et al (2018), com o decorrer dos anos, tem-se aumentado ainda mais as demandas em relação ao atendimento da pessoa com deficiência na Educação Superior. O primeiro desafio apresentado pelas universidades aos recém-chegados é o de torna-los estudantes, afirma Coulon (2008 apud FIGUEIREDO, et al. 2011), destacando que o acesso ao ensino superior não garante o acesso ao saber.

A dificuldade na orientação espacial, segundo Nogueira (2017), é evidenciada quando o usuário está impossibilitado de compreender o espaço, saber onde sua localização e qual direção deve tomar para alcançar seu destino. Um dos fatores que potencializam esse problema é a ausência de uma sinalização direta, precisa e clara, como determina a NBR 9050 (ABNT, 2015), afetando principalmente as pessoas com deficiência.

Dados do IBGE (2010), embora já desatualizados, já demonstravam que aproximadamente $25 \%$ da população brasileira possuía alguma deficiência. Aliado a isso, nas últimas décadas, tem sido cada vez mais frequente o ingresso desses usuários nos ambientes acadêmicos, graças às políticas de inclusão como as cotas, e luta por direitos das pessoas com deficiência. Com isso, evidencia-se a necessidade de se repensar a maneira como as informações acerca do ambiente construído são transmitidas nos espaços universitários, tornando-os mais compreensíveis e consequentemente mais acessíveis, independentemente das limitações das pessoas que os frequentam.

Tendo sua criação datada no ano de 1955, a primeira instituição de ensino superior do Estado da Paraíba ainda hoje carece de um sistema eficiente de orientação para seus usuários. Organizada numa estrutura multi-campi, tem o Campus I como o principal dentre os cinco existentes, que está localizado na cidade de João Pessoa e compreende uma área de 161,75 hectares, de acordo com os dados de Coutinho et al (2010 apud SARMENTO, 2012). Abarca importantes setores administrativos como o edifício da Reitoria, Biblioteca Central e Prefeitura Universitária (UFPB, 2018) por onde transitam diariamente os alunos, professores e funcionários efetivos e terceirizados, além dos visitantes e pessoas que buscam serviços ofertados pela instituição. Tal pluralidade intensifica os desafios para atender as necessidades dos indivíduos dentre os quais, segundo informações coletadas junto ao Comitê de Inclusão e Acessibilidade - CIA (2019), 2.147 são pessoas com deficiência cadastrados ou atendidos pelo comitê. 


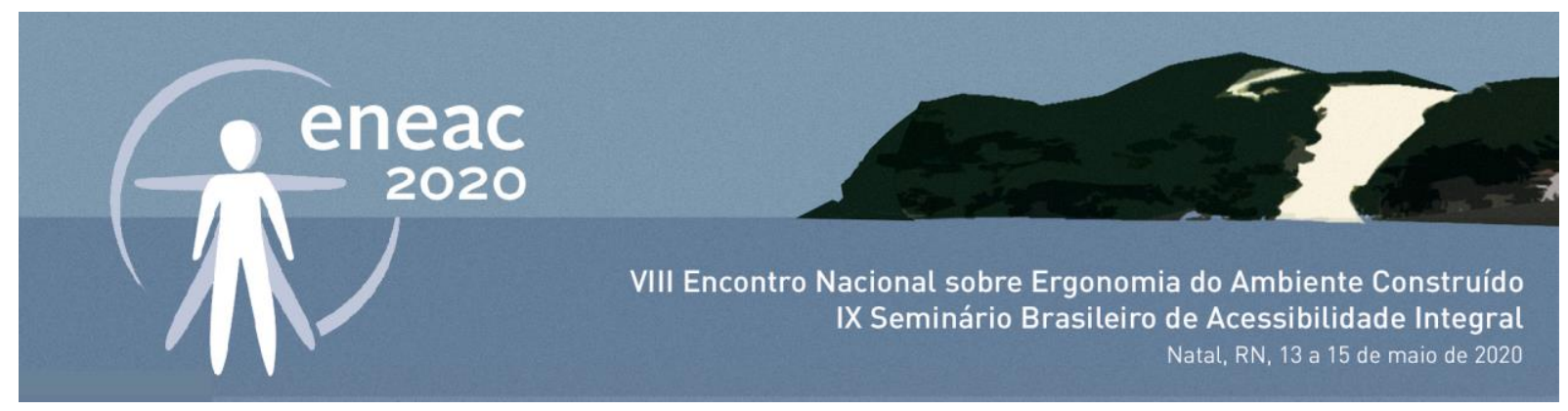

Frente a essa realidade, é necessário reforçar a inclusão social e cidadã dessas pessoas, seguindo as orientações do Estatuto da Pessoa com Deficiência (BRASIL, 2015) que define a acessibilidade como o direito que garante a independência às pessoas com deficiência ou mobilidade reduzida, inclusive nos sistemas educacionais, os quais devem ser acessíveis e inclusivos em todos os níveis de aprendizagem. Um dos fatores que influenciam na acessibilidade - ou ausência dela - são os problemas de infraestrutura comprometendo o deslocamento livre, autônomo e seguro dos usuários. Uma solução arquitetônica de grande importância para contribuir na melhoria da acessibilidade no Campus I da UFPB segundo COSTA (2011) seria o projeto de Rota Acessível definido na NBR 9050 (ABNT, 2015) como trajeto contínuo, desobstruído e sinalizado, que conecte os ambientes e que possa ser utilizado de forma autônoma e segura por todas as pessoas.

É sabido ainda que, por mais bem elaborado que seja, o projeto arquitetônico por si só não soluciona as problemáticas de orientação espacial e deslocamento. É preciso oferecer ao usuário ferramentas de amplo acesso, uma vez que a maneira de compreender o ambiente é variável de acordo com as características pessoais de cada indivíduo, especialmente em relação às pessoas com deficiência visual. Os modelos físicos que, segundo Florio Segall e Araújo (2007 apud MEDEIROS, 2018) ajudam ao deficiente visual experimentar, através do tátil, o espaço real, reconhecendo suas características e elementos, inter-relações e experiências espaciais são os mapas táteis. No estado da Paraíba, desde 2010 está homologada a lei Estadual de no 9.210 que obriga a instalação de mapas táteis e informações em Braille em todos os locais públicos ou privados que apresentem grande circulação de pessoas (PARAÍBA, 2010). Segundo definição de Loch (2007), os mapas táteis são representações gráficas em textura e relevo que servem para orientação e localização de lugares e objetos para portadores de deficiência visual sendo assim um valioso instrumento de inclusão social, uma vez que auxiliam tanto às pessoas com deficiência visual quando às pessoas sem essa deficiência.

Visto as necessidades emergentes do cenário atual, foi desenvolvido, como trabalho de conclusão de curso em arquitetura e urbanismo, um anteprojeto de um Mapa Tátil geral para o Campus I da UFPB como ferramenta para a contribuição direta na orientabilidade dos usuários. $\mathrm{O}$ trabalho aborda as condições de sinalização do Campus I e busca compreender a capacidade que o usuário tem de se orientar de forma autônoma, somado à uma densa pesquisa conceitual e trabalhos já desenvolvidos nesta temática. Agora, este artigo pretende demonstrar a aplicação do método walkthrough como importante etapa metodológica no processo de projetação de um mapa tátil, evidenciando a qualidade nos resultados quando há uma proximidade entre o pesquisador e o espaço em estudo.

\section{METODOLOGIA}

O artigo é fruto de um trabalho de conclusão de curso que adotou, em sua pesquisa, diversas abordagens metodológicas na intenção de garantir os resultados de observação, experimento e levantamento de dados, descritos por KISH (1987 apud Günther, Elali e Pinheiro, 2004) como principais critérios de avaliação. Embora que, individualmente, cada um deles seja incompleto, a combinação dos mesmos promove uma análise mais íntegra e com resultados simultâneos. Os mesmos autores recomendam que a utilização de vários métodos para avaliar o mesmo ponto, classificada como Abordagem Multimétodos é necessária sempre que há uma complexidade no estudo, como é o caso da relação pessoa-ambiente. Para isso, a metodologia adotada foi dividida em 05 etapas, sendo: 1) Levantamento Referencial (documental e bibliográfico), 2) Visitas Exploratórias, 


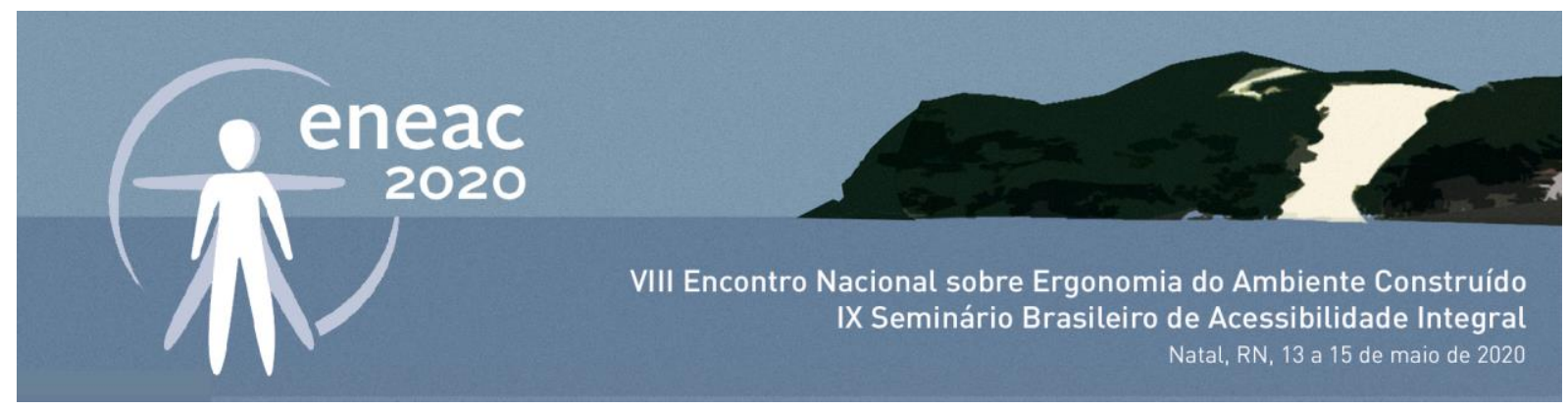

3) Walkthrough, 4) Questionários Online e 5) Entrevistas Semiestruturadas. Contudo, nesse artigo, serão apresentados os resultados do walkthrough.

Trata-se de um método que possibilita ao observador uma familiarização com os espaços, seus usos e principais aspectos. Originário da Psicologia ambiental possibilita, segundo Rheingantz et al (2009), uma caracterização tanto negativa como positiva a partir da descrição do ambiente estudado e desperta no pesquisador às sensações referentes ao espaço em questão. O Walkthrough foi realizado unicamente pelo autor da pesquisa, adotando uma abordagem experiencial, uma vez que o fato de o pesquisador também ser um usuário do Campus I, impossibilitou que houvesse um afastamento crítico. Dessa forma, o pesquisador é estimulado a escrever suas próprias emoções e reações na experiência de relação com o ambiente (RHEINGANTZ ET AL, 2009). Estes mesmos autores recomendam que o método seja aplicado antes de qualquer estudo ou levantamento para que esteja garantida a identificação das problemáticas ambientais e seus usos conforme as percepções do pesquisador. Inicialmente utilizado por Kevin Lynch em 1960, este método permite a verificação da existência (ou inexistência) de ferramentas que contribuam para a orientação e deslocamento dentro do Campus I da UFPB.

Por essa razão o Walkthrough foi aplicado nas primícias da pesquisa, alimentando as etapas metodológicas subsequentes. Para este método, foram utilizados celular com câmera fotográfica e aplicativo de registro de caminhada, uma planta de localização do Campus I fornecida pela Prefeitura Universitária, bloco de papel e caneta para anotações. A realização dessa etapa metodológica aconteceu em 09 fases que, juntas, contemplaram toda extensão territorial do Campus I da UFPB. As fases aconteceram ente os dias 31/01/2019 e 11/02/2019, totalizando os nove percursos alternados entre os turnos da manhã e tarde, durante os quais foram feitos registros fotográficos, anotações, medições e observações que complementaram o desenvolvimento das outras metodologias.

É importante ressaltar que o pesquisador já tinha um contato com o Campus I da UFPB, objeto de estudo desta pesquisa, e que apesar disso, foi necessário realizar uma visita exploratória como método de (re)conhecimento do ambiente. Agora, a partir um olhar técnico, voltado especialmente às relações entre usuários e o meio construído vivenciado, foram comparadas as informações contidas em mapas e plantas fornecidas pela instituição, com o ambiente real.

O número de fases necessárias para concluir o walkthrough é justificado levando em consideração a extensão territorial do Campus I da UFPB, mais de 160 hectares e o fato de que apenas um pesquisador participou desta etapa metodológica. As principais observações eram anotadas na planta de localização do Campus I da UFPB, onde estão representados o sistema de circulação interno e do entorno imediato, as edificações construídas e em processo de construção, lotes vazios, áreas verdes, dentre outras informações. A figura 1 mostra a planta de localização do Campus I da UFPB, cedida pela Prefeitura Universitária durante a etapa de visita exploratória e levantamento documental, foi impressa numa escala 1:2500.

Tendo em mãos a planta com seus respectivos percursos e as 09 rotas pré-definidas, iniciou-se o walkthrough propriamente dito. Ao todo foram 18.740 metros percorridos durante 06 horas e 47 minutos com o registro de 719 fotos. As informações de distância e tempo foram coletadas simultaneamente através do auxílio do aplicativo de celular Strava, disponível gratuitamente e que permite ao usuário gravar em tempo real o caminho percorrido, a distância e tempo gasto. Os números individuais de cada fase podem ser observados na Tabela 1. 


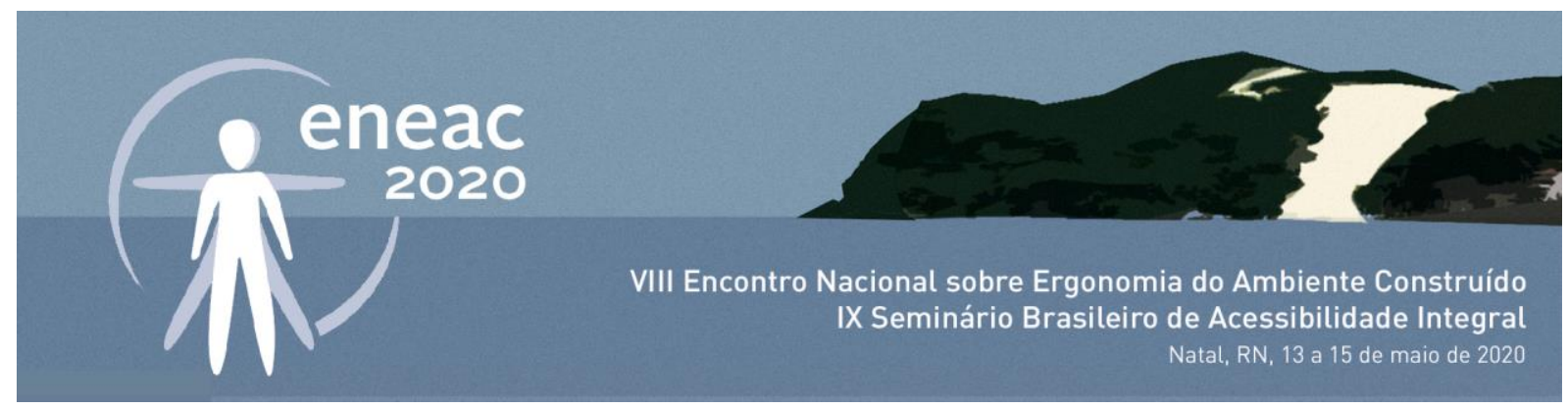

Figura 1: Planta de localização do Campus I da UFPB utilizada no walkthrough

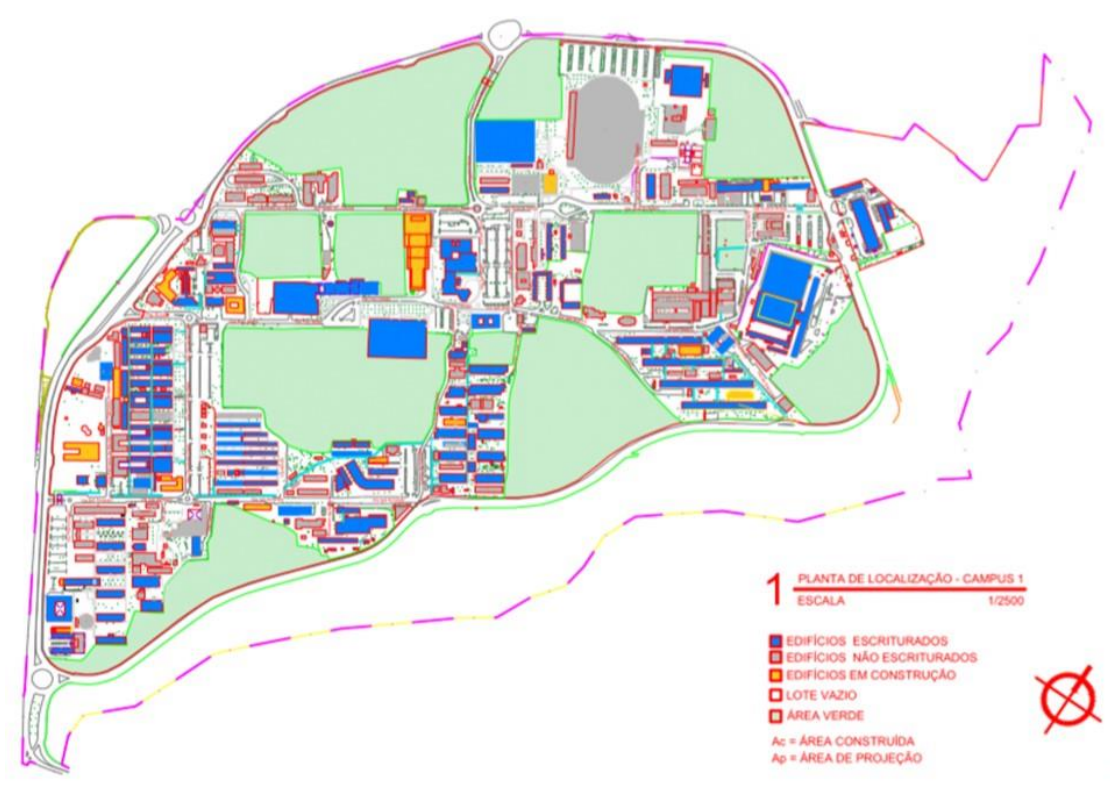

Fonte: Almeida, 2019. 


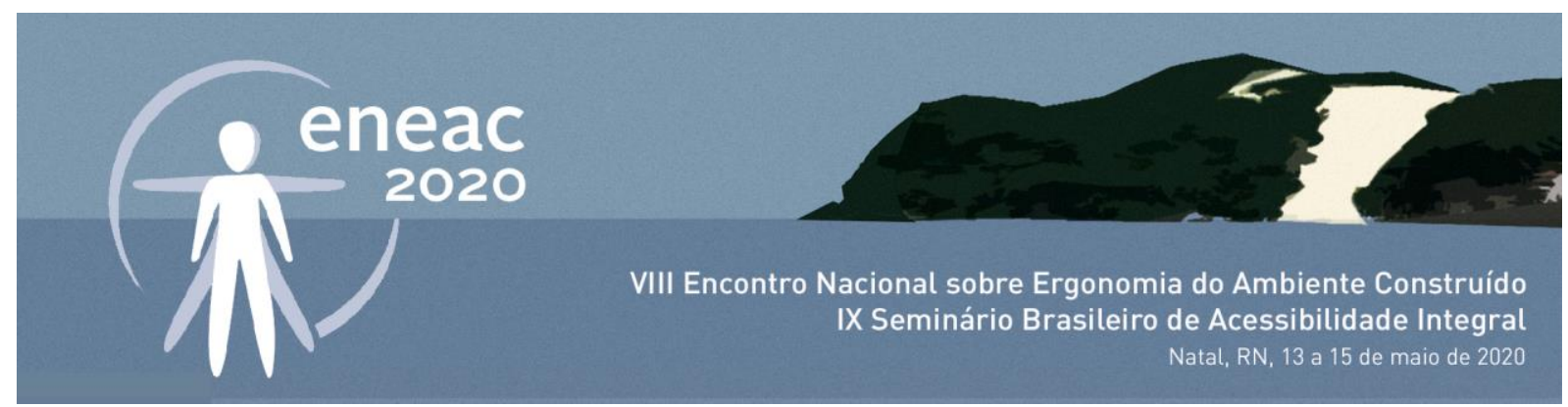

Tabela1: Tabulação dos dados obtidos através de aplicativo de celular durante as 09 fases do Walkthrough.

\begin{tabular}{|c|c|c|c|c|c|c|}
\hline FASE & Dia & Turno & Inicio & $\begin{array}{l}\text { Tempo } \\
\text { Total }\end{array}$ & $\begin{array}{l}\text { Distância } \\
\text { Total }\end{array}$ & $\begin{array}{l}\text { Registros } \\
\text { Fotográficos }\end{array}$ \\
\hline 01 & $31 / 01 / 2019$ & Manhã & $08: 32$ & $\begin{array}{c}1 \mathrm{~h} \\
03 \mathrm{~min}\end{array}$ & $2.930 \mathrm{~m}$ & 84 \\
\hline Trajeto & \multicolumn{6}{|c|}{ Entrada CT; CT; CCJ; CBioTec; Biblioteca CCEN } \\
\hline 02 & $31 / 01 / 2019$ & Manhã & 09:41 & $\begin{array}{c}54 \mathrm{~min} \\
04 \mathrm{~s}\end{array}$ & $2.540 \mathrm{~m}$ & 93 \\
\hline Trajeto & \multicolumn{6}{|c|}{ Entrada CCEN; CCEN; Prédio do STI; CCEN } \\
\hline 03 & $31 / 01 / 2019$ & Tarde & 12:05 & $\begin{array}{l}1 \mathrm{~h} \\
14 \mathrm{~min}\end{array}$ & $3.220 \mathrm{~m}$ & 152 \\
\hline Trajeto & \multicolumn{6}{|c|}{ Entrada CCHLA; CA; CCSA; CE; CCHLA; CEAR } \\
\hline 04 & $31 / 01 / 2019$ & Tarde & $15: 15$ & $\begin{array}{l}39 \mathrm{~min} \\
44 \mathrm{~s}\end{array}$ & 2.300 & 79 \\
\hline Trajeto & \multicolumn{6}{|c|}{$\begin{array}{l}\text { Entrada CCTA; CCTA; Divisão de Patrimônio; TV UFPB; Capela } \\
\text { Ecumênica; DCE; CODISMA; Centro de Vivência; Biblioteca } \\
\text { Central; Restaurante Universitário }\end{array}$} \\
\hline 05 & $05 / 02 / 2019$ & Manhă & 09:00 & $\begin{array}{l}45 \mathrm{~min} \\
07 \mathrm{~s}\end{array}$ & $2.130 \mathrm{~m}$ & 61 \\
\hline Trajeto & \multicolumn{6}{|c|}{$\begin{array}{l}\text { Entrada Reitoria; Segurança UFPB; Reitoria; Almoxarifado; CCS; } \\
\text { Clinica Escola de Fisioterapia }\end{array}$} \\
\hline 06 & $05 / 02 / 2019$ & Manhã & 09:58 & $\begin{array}{l}42 \mathrm{~min} \\
30 \mathrm{~s}\end{array}$ & $1.860 \mathrm{~m}$ & 59 \\
\hline Trajeto & \multicolumn{6}{|c|}{$\begin{array}{l}\text { Entrada Complexo Esportivo; Complexo Esportivo; Creche Escola } \\
\qquad \text { UFPB; CCS }\end{array}$} \\
\hline 07 & $05 / 02 / 2019$ & Manhã & $10: 57$ & $\begin{array}{l}41 \mathrm{~min} \\
44 \mathrm{~s}\end{array}$ & $1.860 \mathrm{~m}$ & 91 \\
\hline Trajeto & \multicolumn{6}{|c|}{$\begin{array}{l}\text { Entrada Residência Universitária; Residência Universitária; CCS; } \\
\text { Prefeitura Universitária; CCS; Prédio de Terapia Ocupacional; } \\
\text { Entrada CCS }\end{array}$} \\
\hline 08 & $09 / 02 / 2019$ & Manhã & $11: 02$ & $\begin{array}{c}33 \mathrm{~min} \\
25 \mathrm{~s}\end{array}$ & $1.280 \mathrm{~m}$ & 89 \\
\hline Trajeto & \multicolumn{6}{|c|}{ Entrada $\mathrm{CM} ; \mathrm{CM}$; CCS } \\
\hline 09 & $11 / 02 / 2019$ & Tarde & $15: 43$ & $\begin{array}{c}13 \mathrm{~min} \\
50 \mathrm{~s}\end{array}$ & $720 m$ & 29 \\
\hline Trajeto & \multicolumn{6}{|c|}{ Entrada HU; HU; Entrada HU } \\
\hline
\end{tabular}

Ao término das 09 fases do walkthrough, foi constatado que todos os setores do Campus, seus centros de ensino, edificações importantes e espaços de convívio foram contemplados. A escolha dos percursos priorizou os caminhos regulares, reconhecidos oficialmente pela Prefeitura Universitária. $\mathrm{Na}$ falta destes, caminhos intuitivos ou vivenciados por outros usuários eram escolhidos e utilizados. O início de cada fase se deu nos acessos, de forma que todos eles fossem contemplados.

Com base nas informações gráficas fornecidas pelo aplicativo Strava, foi possível transcrever o mapeamento dos percursos para o programa Quantum Gis (QGis), também disponibilizado gratuitamente para download e utilizado na produção e edição de mapas. Partindo de uma base cartográfica da UFPB fornecida pela Prefeitura Universitária, foram traçados no QGis as mesmas rotas geradas pelo aplicativo e em seguida houve uma compilação das 09 fases, vista na Figura 2, e cujos resultados serão discutidos. 

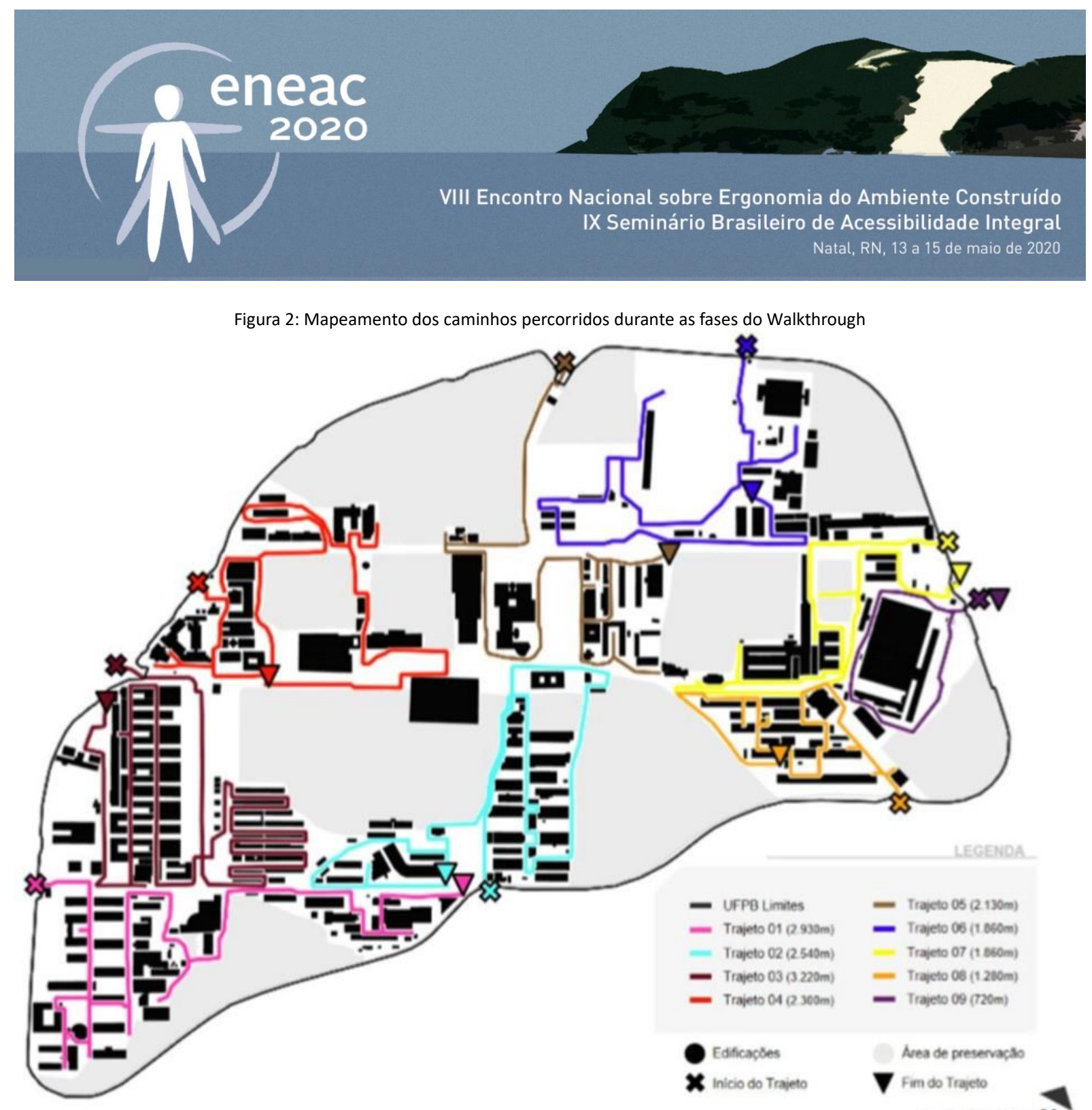

ESCALA 1:5000 N

Fonte: Almeida, 2019.

\section{A ESSÊNCIA PERCEBIDA: RESULTADOS DO WALKTHROUGH}

Esta etapa revelou ainda uma fragilidade na relação das pessoas que circulavam com o ambiente físico-ambiental do campus, tendo como principal motivação, a dificuldade de orientação. Durante as etapas do walkthrough, além dos registros de distância, tempo e percurso obtidos através do aplicativo Strava, foram registradas 719 fotos. Para organizar o material coletado durante o walkthrough, foi elaborada uma planilha com todos os registros de placas informativas, letreiros, avisos e demais dispositivos de sinalização presentes no espaço físico da UFPB. Duas colunas classificam as informações quanto existência desta no ambiente. As informações provisórias são elencadas seguindo a sequência dos registros enquanto as informações instaladas de forma permanente são subdivididas quanto ao estado de conservação. Essa planilha foi produzida na intenção de facilitar a análise das sinalizações e fomentar as discussões desse artigo. 


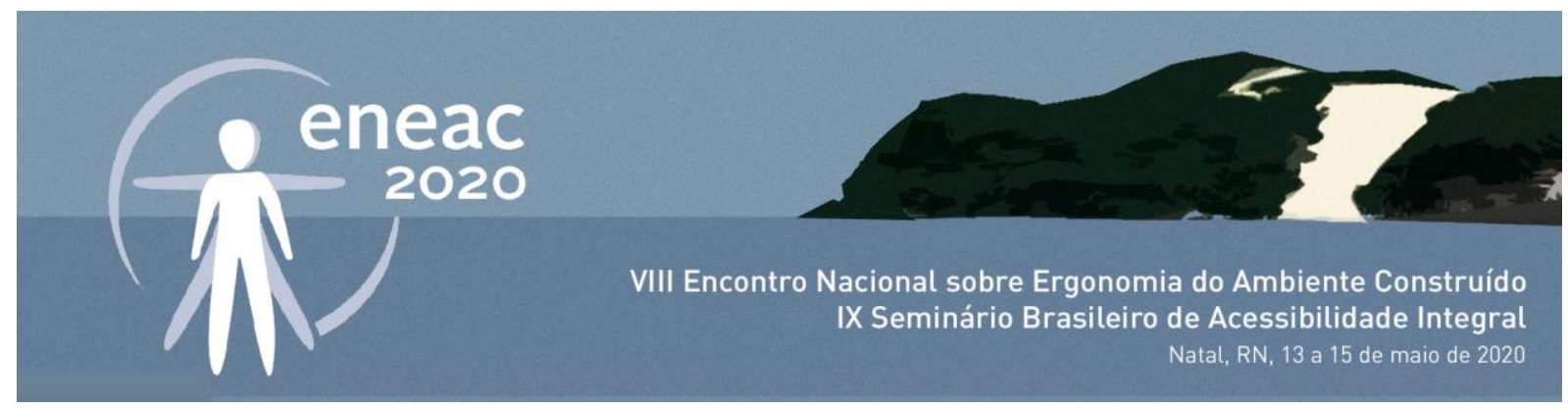

Quanto ao uso, apropriação, conservação, estrutura dos espaços, os registros identificaram alguns pontos positivos do Campus I: os bolsões de mata atlântica, onde o Campus está inserido, servindo como ponto de orientação; a presença, em alguns trechos, de passarelas cobertas, calçadas e faixas de pedestre, elementos básicos para garantir um movimento pedonal confortável e eficiente; sinalização tátil no piso (direcional e de alerta).

Porém, em sua maioria, os percursos registrados nas fotografias evidenciam trechos de calçadas com piso irregulares, travessia de vias sem faixa de pedestre e até calçadas sem conexão ou obstruídas por canteiros de obra; apesar de existirem muitas rampas com o símbolo de acessibilidade ou pintadas na cor padrão azul, poucas delas podem ser consideradas de fato acessíveis, seja pela ausência de corrimão e parapeito, seja pela inclinação visivelmente em desacordo com o recomendado pela NBR 9050.

Além das já citadas barreiras físicas, outro fator que agrava os problemas de acessibilidade dentro do campus I da UFPB são as barreiras atitudinais, definida pela Lei de Brasileira de Inclusão - LBI como atitudes ou comportamentos que geram prejuízos aos direitos e socialização da pessoa com deficiência (BRASIL, 2015), ou seja, quando as ações dos indivíduos limitam o acesso de determinado grupo de pessoa. As barreiras atitudinais puderam ser registradas e ocorrem de maneiras distintas em todos os setores explorados no walkthrough: automóveis estacionados nas calçadas, material acumulado impedindo ou dificultando a passagem dos pedestres entre outras formas.

Por fim, encontraram-se ainda inúmeras barreiras de comunicação, outro tipo de barreira constatada no Campus I; definidas pela Lei Brasileira de Inclusão como qualquer atitude ou obstáculo que impossibilite comunicação de uma mensagem ou informações por intermédio de sistemas de comunicação e de tecnologia da informação (BRASIL, 2015). Essa barreira de comunicação pode acontecer tanto na ausência de ferramentas suficientes para que o usuário possa se deslocar nos espaços físicos, quanto pelo excesso de informação como ambientes sobrecarregados de placas, avisos e propagandas que causam uma poluição visual e gera uma confusão mental no processo dessas informações, ofuscando, muitas vezes a que seria fundamental para a compreensão ambiental.

Durante os 09 percursos, não foram encontrados quaisquer tipos de sinalização sonora; e apenas 02 exemplares de Mapas Táteis: o primeiro, localizado no Centro de Tecnologia - CT (COSTA, et al 2018) que identifica as principais edificações do CT relacionadas com o curso de Arquitetura e Urbanismo, também os laboratórios ligados ao curso e está instalado na área externa da coordenação. $O$ segundo mapa tátil (SARMENTO, 2009) está localizado no centro de educação e trata de um mapa geral do campus I, está, contudo, desatualizado e com sinais de deterioração. Também fixado em parede, se encontra ao lado do Núcleo de Educação Especial - NEDESP. Esses mapas táteis podem ser vistos na Figura 3. 


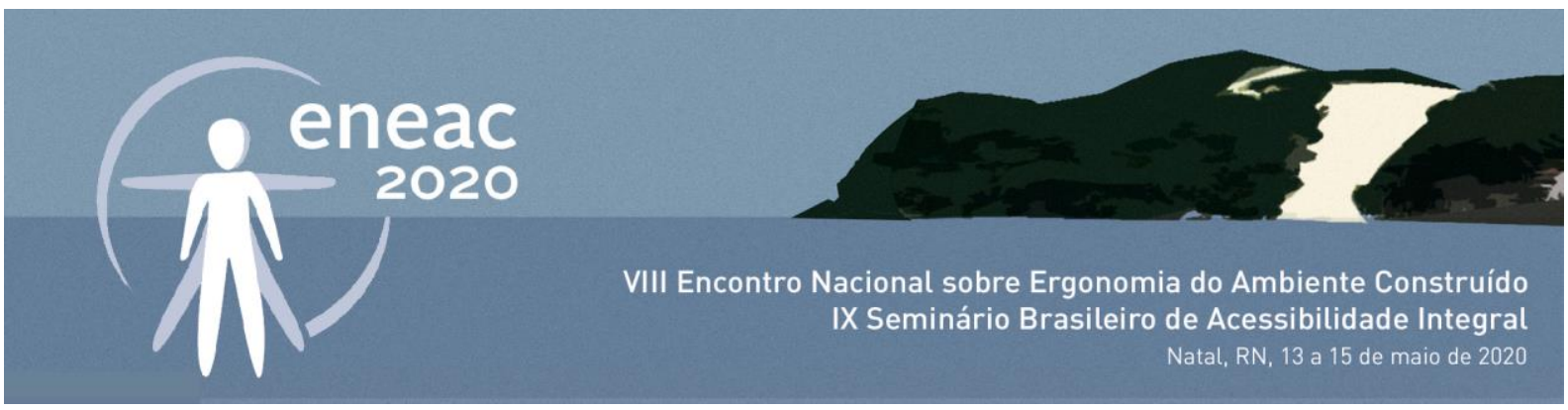

Figura 3: Mapas Táteis referentes ao Campus I encontrados durante o Walkthrough
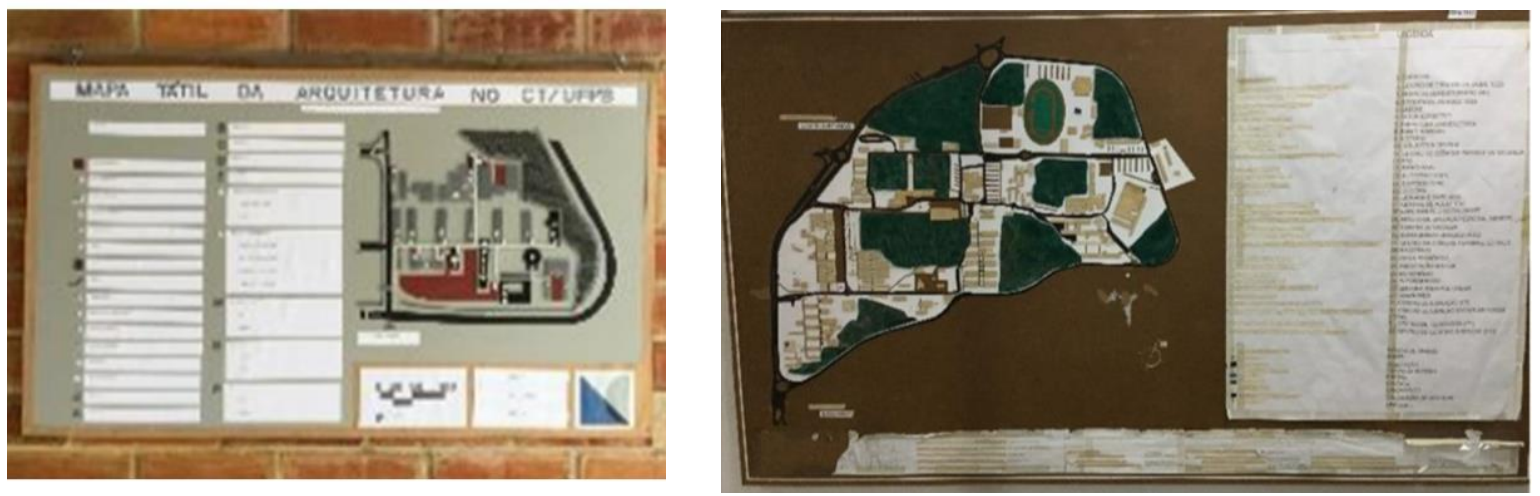

Fonte: Almeida, 2019.

A identificação dos centros acadêmicos e seus respectivos edifícios está distante do aceitável e o mesmo ocorre com os acessos à UFPB: apenas 03 das 09 entradas são sinalizadas e informam que se trata de um espaço da instituição, que são: Centro de Tecnologia - CT, Reitoria e Residência Universitária; todas com uma estrutura marcante e identificação oficial da UFPB. Já os acessos do Centro de Ciências Humanas, Letras e Artes - CCHLA e Complexo Esportivo, apesar de apresentarem guaritas, não têm identificação. As entradas do Centro de Ciências da Saúde - CCS, do Centro de Ciências Exatas e da Natureza - CCEN, do Centro de Comunicação, Turismo e Arte - CCTA e do Centro de Ciências Médicas, não possuem sequer guarita ou identificação. $O$ mesmo acontece com os Centros de Ensino e as principais edificações do Campus I da UFPB, já que nem todos são identificados e quando o são, não apresentam fontes, tamanho e material padronizado, também são variados os locais e maneira de instalação dos letreiros.

Com intuito de observar melhor e realizar uma análise comparativa dos locais que possuem e não possuem identificação, bem como sua tipologia, foram confeccionados 4 mapas que destacam as principais edificações encontradas durante o Walkthrough. No mapeamento (Figura 4) é possível perceber as particularidades de cada percurso, mas que, de maneira geral, apresentam as mesmas carências na identificação das edificações e orientação básica para deslocamento.

Foi registrado, de maneira geral que as principais edificações dos centros acadêmicos de ensino não possuem uma identificação clara e objetiva. As ruas não possuem identificação e são poucos os corredores de circulação para pedestres que apresentam placas ou letreiros informando salas de aula, administrativo ou blocos diferentes. Ao analisar as poucas placas informativas desconsiderando as em precário estado de conservação - ficou evidente a inexistência de um padrão de forma, fonte gráfica e paleta de cores para o Campus I da UFPB, o que dificulta ainda mais o entendimento da informação transmitida. 


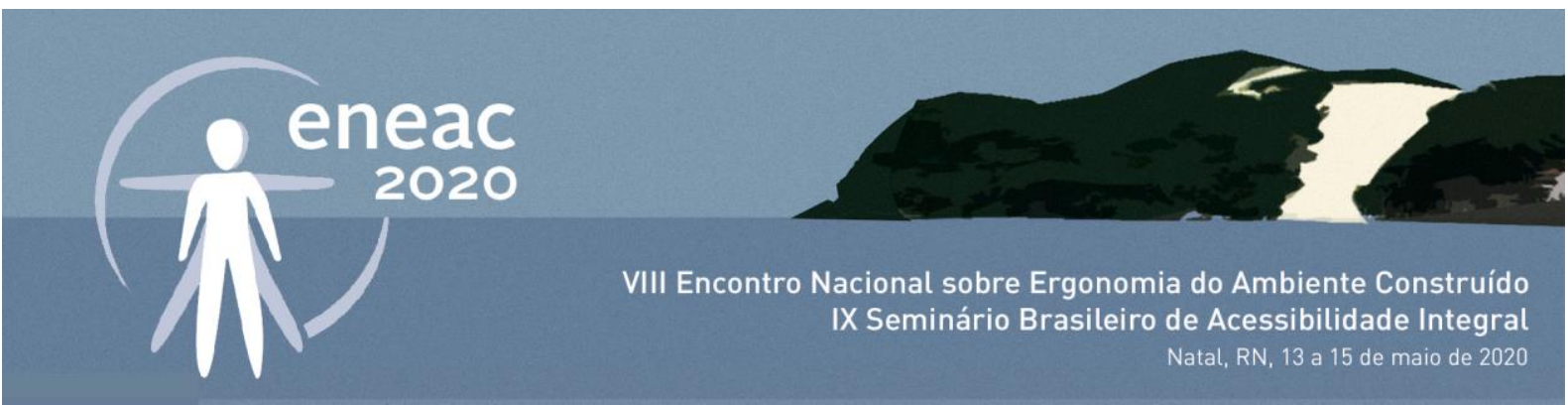

Figura 4: Mapeamento para análise da presença da sinalização nas principais edificações durante as fases 01 e 02 do Walkthrough.

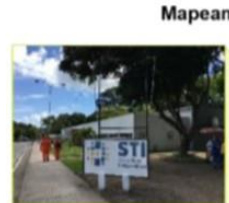

apeamento para análise da presença da sinalização nas principais edificaçōes
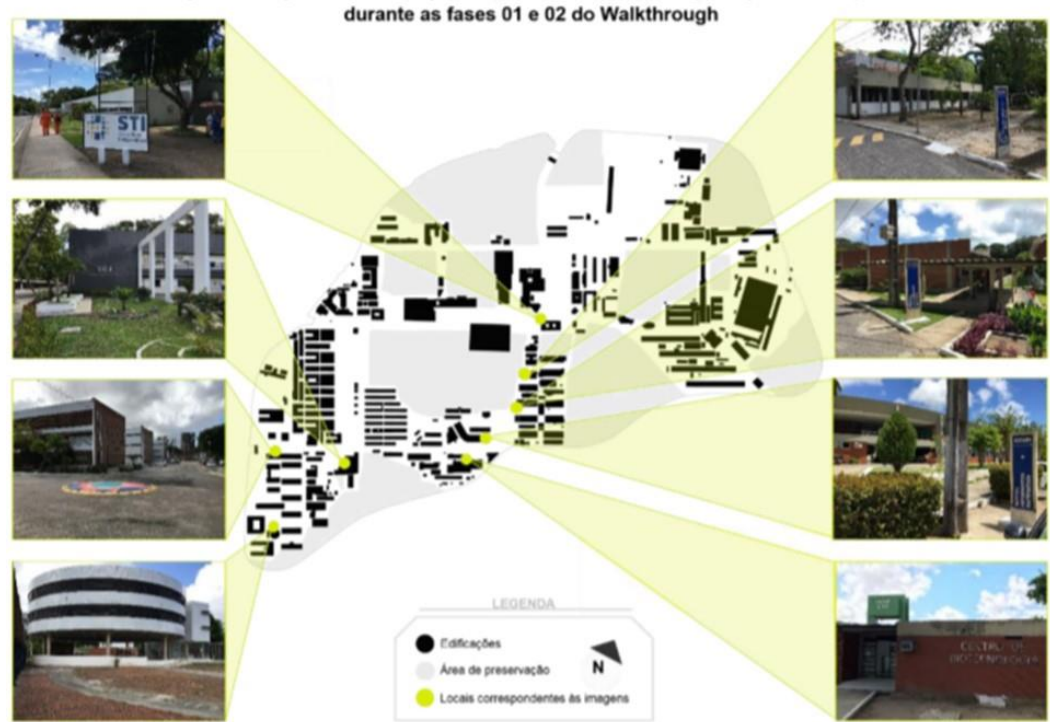

Fonte: Almeida, 2019

As observações realizadas durante o walkthrough juntamente com os registros fotográficos e dados fornecidos pelo aplicativo Strava serviram como parâmetros fundamentais para conferência das informações contidas na planta de localização do Campus I. As edificações foram checadas e as existentes - com exceção das em construção - foram computadas, gerando um Mapa de Nolli das edificações do Campus I (Figura 5).

Figura 5: Mapa de Nolli das edificações existentes no Campus I da UFPB.

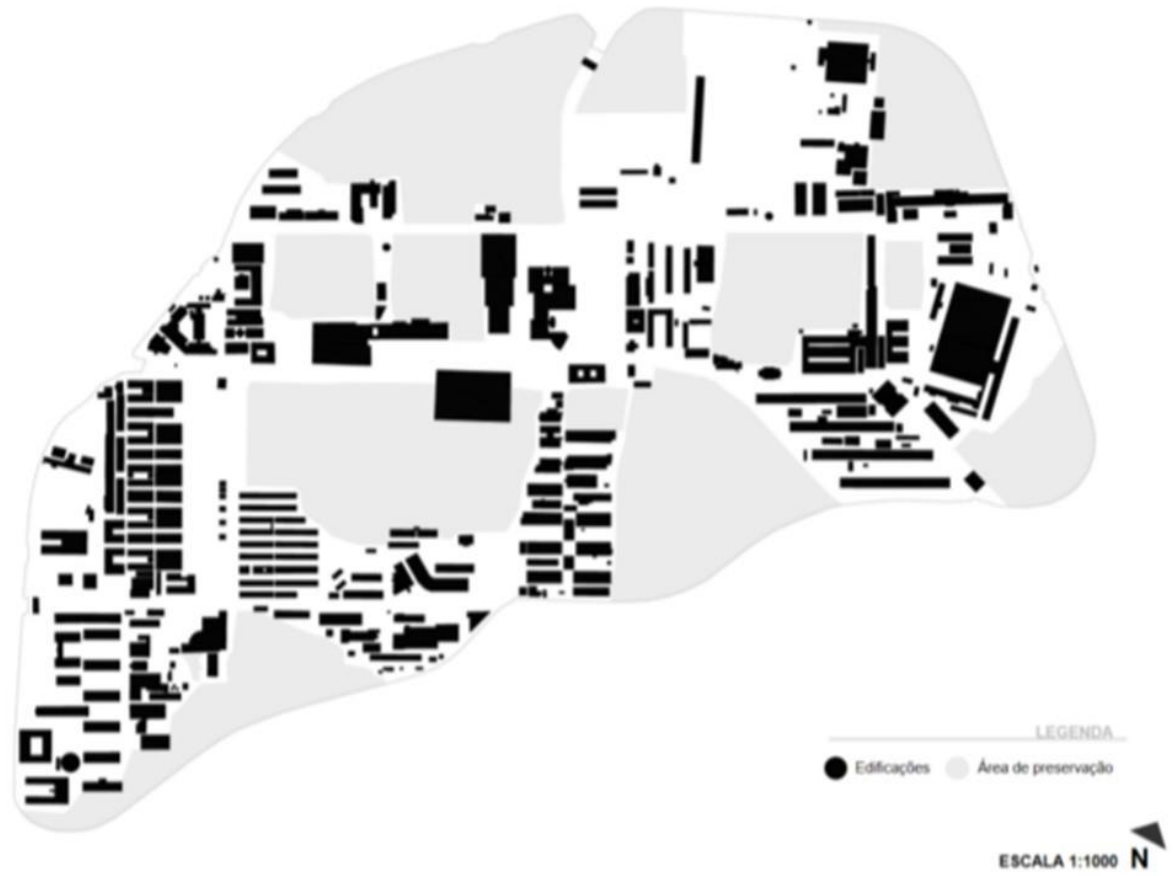

Fonte: Almeida, 2019. 


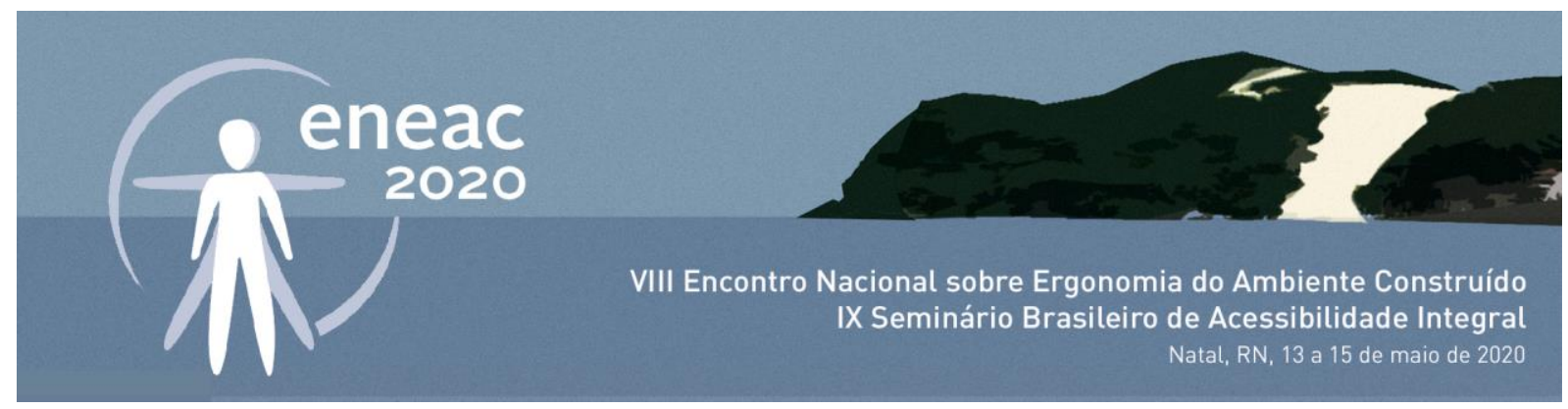

Esse primeiro mapa demonstra que a grande quantidade de edificações dispostos no território universitário, torna ainda mais complexo o desafio de tornar esse ambiente acessível, especialmente no sentido de permitir a orientação espacial de seus usuários e um fácil processo de deslocamento dos mesmos. Outro destaque importante é a inserção da instituição numa área de preservação ambiental, o que acaba condicionando o crescimento físico da universidade. Para fins de estudo para localização dos mapas táteis, o mapa noli das edificações traz uma contribuição muito importante pois permite um estudo de concentrações de edificações, centralidade espacial e hierarquia das edificações.

O mesmo processo foi utilizado para produção de um novo mapa do sistema de circulação interno do Campus I, as informações contidas na planta de localização foram confrontadas com as experiências em campo e alguns ajustes precisaram ser feitos. As calçadas e passarelas cobertas foram consideradas como um único sistema de circulação de pedestre e os estacionamentos irregulares foram considerados juntamente com os regulares a fim de apresentar um resultado mais fidedigno com a realidade existente. Foram então produzidos três mapas de Nolli distintos: das vias de automóveis, dos estacionamentos regulares e irregulares e das calçadas e passarelas cobertas para pedestre. A sobreposição dos três resultou no mapa do sistema de circulação interno da UFPB e pode ser conferido na Figura 6.

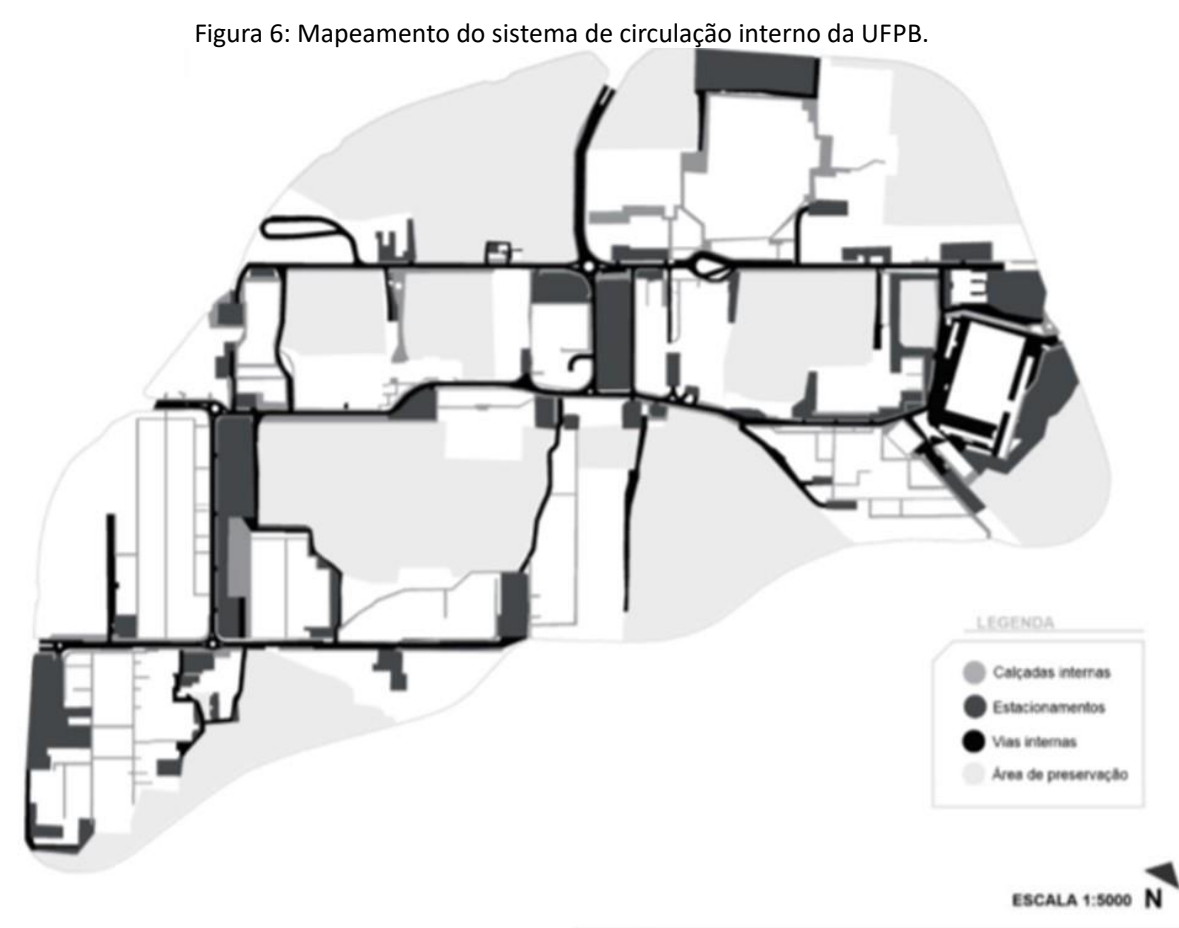

Fonte: Almeida, 2019.

Com a análise dos fluxos foi possível compreender a complexidade no sistema de circulação interna do Campus, apesar de só estarem computados as vias regulares. Com essa informação, é de se esperar que o sistema de informações e orientações deva acompanhar a mesma complexidade, sendo preciso, inclusive, pensar em um sistema com níveis diferentes. 


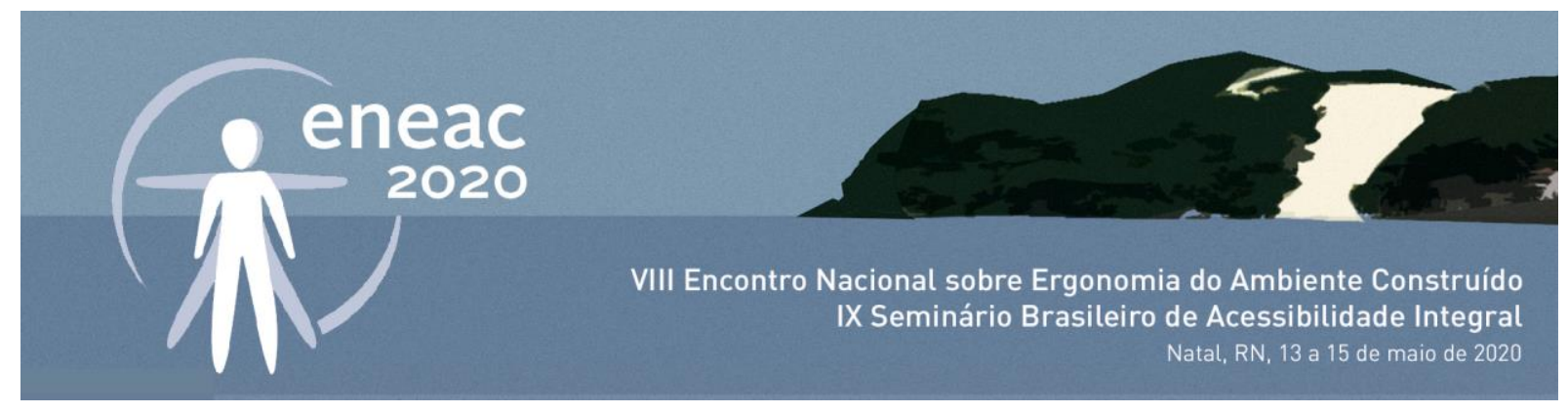

\section{CONSIDERAÇÕES FINAIS}

Os mapas de Nolli das edificações e o mapeamento do sistema de circulação foram utilizados como bases cartográficas no processo de generalização das informações reais para confecção de mapas táteis (LOCH, 2009). Os resultados desta etapa metodológica serão confrontados com as respostas obtidas no questionário online, no intuito de comparar as opiniões dos usuários e pesquisador, enriquecendo os resultados e propostas de solução.

As atividades realizadas na Visita Exploratória e no Walkthrough proporcionaram um contato inicial essencial e único com o espaço físico-ambiental, edificações e usuários do Campus I da UFPB além de uma compreensão da relação pessoa-ambiente experienciada ao longo dos percursos. A organização e análise do material coletado resultaram no mapeamento das principais vias, identificação das edificações e das sinalizações presentes no Campus. Ainda como resultado dessa etapa metodológica, foi possível categorizar os dispositivos de sinalização e classificá-los quanto à eficácia. Nas fases posteriores, foram introduzidas as apreensões dos usuários, coletadas através da aplicação de questionário online e entrevista semiestruturada.

Desta forma, fica comprovada a importância da aplicação do método walkthrough no processo de projetação de Mapas Táteis uma vez que há uma aproximação muito bem-vinda do pesquisador com o ambiente em estudo e proporcionando uma coleta de dados e informações fundamentais para as decisões projetuais de uma ferramenta de orientação espacial.

\section{REFERÊNCIAS}

ABNT. NBR 9050/2015. Acessibilidade a Edificações, Mobiliário, Espaços e Equipamento Urbanos. Rio de Janeiro: ABNT, 2015.

ALMEIDA, Eduardo Augusto Monteiro de. Anteprojeto de dispositivo de orientação espacial: mapa tátil-visual para o campus I da UFPB / Eduardo Augusto Monteiro de Almeida. - João Pessoa, 2019.

Casa Civil. Lei № 13.146, de 6 de julho de 2015. Lei Brasileira de Inclusão da Pessoa com Deficiência (Estatuto da Pessoa com Deficiência). Brasília, 2015. Disponível em:

<http://www.planalto.gov.br/ccivil_03/_ato20152018/2015/lei//13146.htm> Acesso em outubro de 2018. BRASIL, Presidência da República.

COSTA, Angelina Dias Leão; SILVA, Dandara Souza; ALMEIDA, Eduardo Augusto Monteiro; GADE, Mélody; GROSSE, Maxime; SARMENTO, Bruna Ramalho. Representação gráfica tridimensional como ferramenta auxiliar para localização e deslocamento. Laboratório de Acessibilidade. UFPB. João Pessoa. 2018.

COSTA, Angelina Dias Leão. UFPB para todos: eliminando barreiras. Projeto Incluir 2010. Ministério da Educação. Secretaria de Educação Superior. UFPB. João Pessoa. 2011.

FIGUEIREDO, AC., et al. Acessibilidade e vida universitária: pontuações sobre a educação inclusiva. In: SAMPAIO, SMR., org. Observatório da vida estudantil: primeiros estudos [online]. Salvador: EDUFBA, 2011, pp. 187-207. ISBN 978-85-2321211-7. Available from SciELO Books .

GARCIA, Raquel Araújo Bonfim; BACARIN, Ana Paula Siltrão; LEONARDO, Nilza Sanches Tessaro. Acessibilidade e permanência na educação superior: percepção de estudantes com deficiência. Psicol. Esc. Educ., Maringá, v. 22, n. spe, p. 33-40, 2018. Disponível em <http://www.scielo.br/scielo.php?script=sci_arttext\&pid=S1413$85572018000400033 \&$ Ing=pt\&nrm=iso >. acessos em 21 jan. 2020.

INSTITUTO BRASILEIRO DE GEOGRAFIA E ESTATÍSTICA (IBGE). Censo Demográfico e Contagem da População: Universo Características da população e do domicilio. Rio de Janeiro, 2010. Disponível em: <http://www.sidra.ibge.gov.br > Acesso em agosto de 2018. IPS.

LOCH, Ruth Emília Nogueira; ALMEIDA, de Luciana Cristina. O projeto "mapas táteis como instrumentos de inclusão social de 


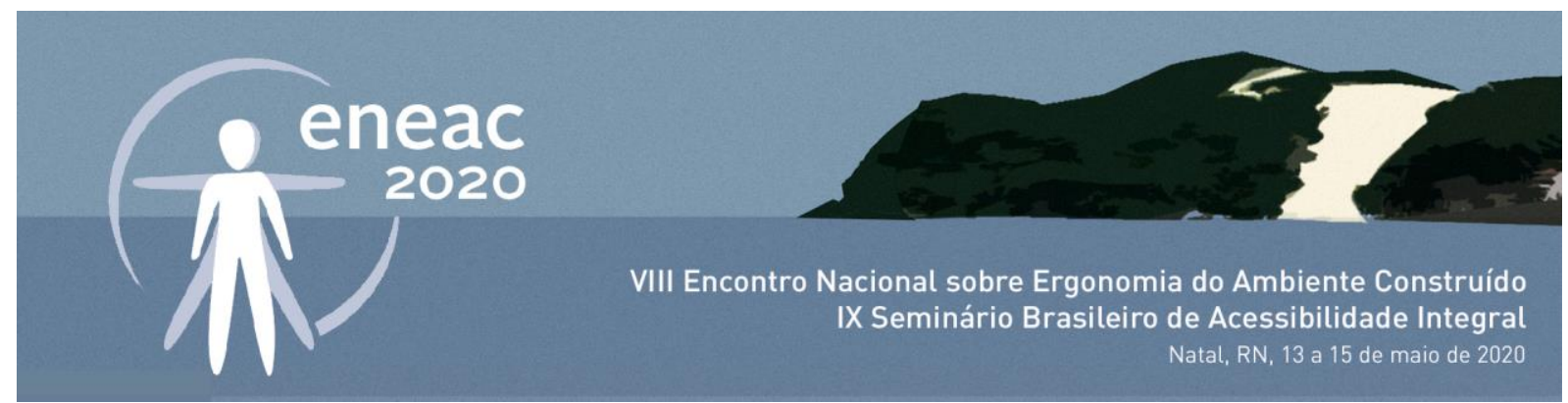

portadores de deficiência visual'". In: Seminário Nacional Interdisciplinar em Experiências Educativas - SENIEE, 2007, Francisco Beltrão, PR. 2007.

MEDEIROS, Ana Thereza Faria de. Projetando no silêncio: estratégias para participação de pessoas surdas em projetos de arquitetura residencial. Dissertação (Mestrado em Arquitetura e Urbanismo) - Centro de Tecnologia, Universidade Federal do Rio Grande do Norte. Natal, 2018.

NOGUEIRA, Dhyego Lima. Wayfinding e legibilidade ambiental em parque urbano: Um estudo da percepção de usuários idosos. Dissertação de mestrado, Programa de Pósgraduação em Arquitetura e Urbanismo, UFPB, João Pessoa, 2017.

PARAÍBA, Câmara dos Deputados. Lei estadual número 9.210, de 23 de agosto de 2010. João Pessoa, 2010. Disponível em: <http://static.paraiba.pb.gov.br/diariooficial_old/diariooficial30112010.pdf> Acesso em novembro de 2018. PROJETO ACESSO. O código Braille. Disponível em: <www.projetoacesso.org.br/site/index.php/deficiencia-visualconceituacao/Braille> Acesso em: abril de 2019

RHEINGANTS, Paulo Afonso; AZEVEDO, Giselle Arteiro; BRASILEIRO, Alice; ALCANTARA, Denise; QUEIROZ, Mônica. Observando a qualidade do lugar: Procedimentos para a avaliação pós ocupação. Rio de Janeiro: Proarq/FAU/UFRJ 2009.

SARMENTO, Bruna Ramalho. Acessibilidade em Sistema de Circulação de Pedestres. João Pessoa, 2012. Dissertação (Mestrado em Arquitetura e Urbanismo) - Centro de Tecnologia, Universidade Federal da Paraíba. 2012

SARMENTO, Bruna Ramalho; LIMA, Aluizia Márcia Fonseca de Lima. Percepção espacial de deficientes visuais: Maquete tátil como auxílio para locomoção no campus I da Universidade Federal da Paraíba. Revista Eletrônica Extensão Cidadã. João Pessoa-PB, 2009.

Universidade Federal da Paraíba (UFPB). Sobre a UFPB. Disponível em <http://www.ufpb.br/content/ufpb >. Acesso em agosto de 2018 Universidade Federal da Paraíba (UFPB). UFPB 50 ANOS. Edição Comemorativa pelo Jubileu de Ouro da Fundação da Universidade Federal da Paraíba. Editora Universitária, João Pessoa, 2006. 